\title{
The Contrastive Analysis of the Energy Consumption Characteristics of China and the United States
}

\author{
Xingjin $\mathrm{Yu}$ \\ Department of Economic Management \\ North Chinese Electric University \\ Hebei,China \\ yxjbb123@163.com
}

\begin{abstract}
Energy is the material basis for the national economic and social development, the modern society, with increasing productivity level, the energy demand is growing, the whole society for energy dependence is becoming more and more big. But we can't ignore the increasingly high speed growth in energy demand and energy scarcity of contradictions. This paper adopts the method of case analysis and comparative analysis, respectively from the total energy consumption characteristics, energy consumption, energy consumption characteristics analysis between our country and the United States for nearly a decade of energy consumption characteristics, comparing differences between energy consumption between China and advanced countries, and the problems existing in the energy consumption in China put forward the corresponding Suggestions. Our country can fully tap the potential of renewable energy value, change the traditional pattern of energy consumption, looking for a new growth point of energy.
\end{abstract}

Keywords-Energy consumption structure; Comparison and analysis; Renewable energy sources; Economic bottlenecks

\section{INTRODUCTION}

Energy as a potential power of economic growth, is closely related to our daily life, the energy consumption structure, understand the present situation of energy consumption in our country is closely related to our life.

The United States is the world's energy consumption is the first big country, China ranked second, but the energy consumption of our country there are serious structural imbalances, China's long-term economic growth is the core of energy-intensive industries. The serious destruction of environment in our country, in recent years bring environmental governance is very heavy burden. So this kind of economic growth mode is impossible to continue for a long time, our country must be profoundly aware of the traditional energy consumption structure is given priority to with coal has no longer meet the requirement of our country want to maintain high economic growth. And the United States in response to the world energy security and climate change, has put forward the energy strategy of "all-round", its energy structure are facing huge change. Therefore, as the second largest energy consumer, we also deal with the global environmental problems to respond. In this article, through comparative analysis our country energy dissipation

\section{ANALYSIS OF CHARACTERISTICS OF CHINA'S ENERGY CONSUMPTION}
A. The total amount of China's energy consumption analysis

Table 1-2003 to 2013, the total energy consumption in our country

Units: one million tons of oil equivalent (Mote)

\begin{tabular}{lllllll}
\hline Year & 2003 & 2004 & 2005 & 2006 & 2007 & 2008 \\
\hline Gross & 1204.2 & 1423.5 & 1566.7 & 1729.8 & 1862.8 & 2002.5 \\
\hline Year & - & 2009 & 2010 & 2011 & 2012 & 2013 \\
\hline Gross & - & 2187.7 & 2432.2 & 2613.2 & 2735.2 & 2852.4 \\
\hline
\end{tabular}

Data sources: China natural gas industry network

( http://www.cngascn.com/html/news/show_news_w1_1 29929.html)

Table 2-2003-2013 China all kinds of one-off energy consumption structure (\%)

\begin{tabular}{lllllll}
\hline Year & $\begin{array}{l}\text { Crude } \\
\text { Oil }\end{array}$ & $\begin{array}{l}\text { Nat } \\
\text { Gas }\end{array}$ & Coal & $\begin{array}{l}\text { Nuclear } \\
\text { Energy }\end{array}$ & $\begin{array}{l}\text { Hydro } \\
\text { Power }\end{array}$ & $\begin{array}{l}\text { Renewa } \\
\text { ble } \\
\text { Energy }\end{array}$ \\
\hline 2003 & 22.1 & 2.4 & 69.3 & 0.8 & 5.3 & \\
2004 & 22.4 & 2.5 & 68.7 & 0.8 & 5.6 & \\
2005 & 20.9 & 2.6 & 69.9 & 0.8 & 5.7 & \\
2006 & 20.4 & 2.9 & 70.2 & 0.7 & 5.7 & \\
2007 & 19.5 & 3.4 & 70.5 & 0.8 & 5.9 & \\
2008 & 18.8 & 3.6 & 70.2 & 0.8 & 6.6 & \\
2009 & 17.7 & 3.7 & 71.2 & 0.7 & 6.4 & 0.3 \\
2010 & 17.6 & 4 & 70.5 & 0.7 & 6.7 & 0.5 \\
2011 & 17.7 & 4.5 & 70.4 & 0.7 & 6 & 0.7 \\
2012 & 17.7 & 4.7 & 68.5 & 0.8 & 7.1 & 1.2 \\
2013 & 17.8 & 5.1 & 67.5 & 0.9 & 7.2 & 1.5 \\
\hline
\end{tabular}

Data sources: China natural gas industry network

( http://www.cngascn.com/html/news/show_news_w1_1 _29929.html)

Can be seen from table 1, the energy consumption in China is mainly composed of raw coal, crude oil, natural 
gas, nuclear energy, hydro power and renewable energy. Figure 1 shows that the total energy consumption in China increased year by year, from 2003, 1.2042 billion oil equivalent refresh to 2.8524 billion oil in 2013 .

B. Analysis of characteristics of the composition of China's energy consumption

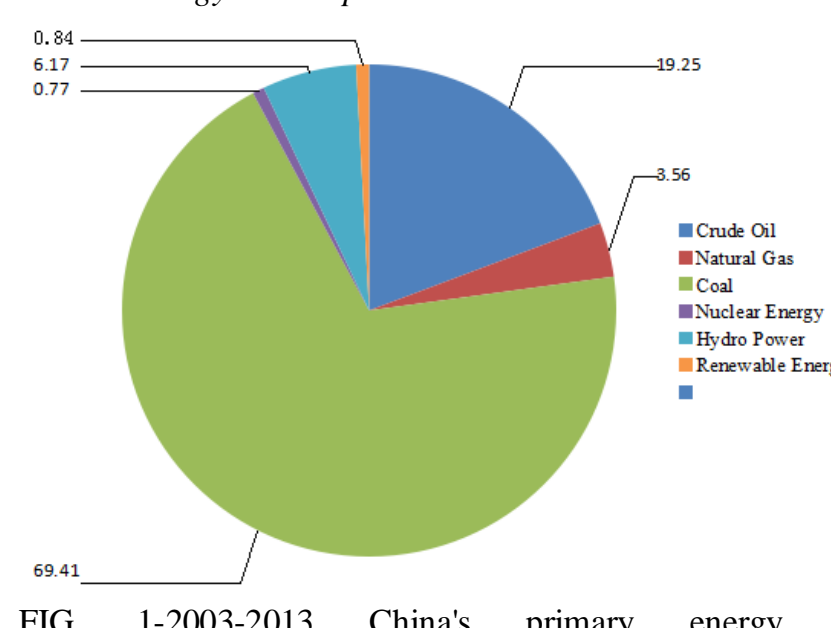

FIG. 1-2003-2013 China's primary energy consumption ratio $(\%)$

From figure 1, you can see, our energy is mainly composed of raw coal, crude oil, natural gas, nuclear power, hydropower, renewable energy, and raw coal consumption in China has been dominant for a long time, from 2003 to 2013, the average coal consumption accounted for about $69.41 \%$ of the total energy consumption, and the average oil consumption accounts for about $19.25 \%$ of the total energy consumption, the second is hydropower, about $6.17 \%$ of the total energy, and natural gas, nuclear energy, renewable energy accounted for an average of only $5.17 \%$ of the total energy. We can find that, our country is a typical traditional is given priority to with coal energy consumption structure, consumption of raw coal and crude oil has reached around $80 \%$ of the total energy consumption, about four times that of other one-time renewable energy.

\section{Analysis of characteristics of the growth of China's energy consumption}

Can be seen from table 1, the total energy consumption in China in the recent ten years continued to grow, but the pace of growth is slower, from 2003 to 2013, the total energy consumption in our country always increases by $136.9 \%$, the average annual growth of $9.0 \%$. As can be seen from table 2, China's coal consumption from 2003 to 2010 increased by $2.7 \%$, the average annual growth of $0.45 \%$. Peaked in 2010 after the fall, fell by $5.2 \%$, a $0.8 \%$ drop in annual average. Crude oil consumption from 2003 to 2013 , have continued to decline, fell by $20.5 \%$, a $2.1 \%$ drop in annual average. Gas consumption continues to grow, with a total growth of $12.5 \%$, the average annual growth of $7.8 \%$. Hydroelectric power consumption from 2003 to 2010, also continue to increase.Overall growth was $26.4 \%$, the average annual growth of $3.4 \%$; But in 201 , hydroelectric power consumption fell, fell by $10.4 \%$, compared with 2010 in 2012 and then 2013 hydroelectric power consumption and reached a new stage, compared with $20 \%$ growth in 2011. However, nuclear energy consumption has been accounted for only about $0.77 \%$ of the energy consumption in our country, its consumption is not very big growth. Renewable energy as a kind of modern economic society proposed new energy to solve the problem of energy crisis, with its peculiar resilience and sustainability are favored by countries around the world, but our country although renewable energy consumption continues to grow, but accounted for the proportion of total energy consumption is quite low, only $0.84 \%$

\section{Brief Summary}

To sum up, in the past decade, China's energy consumption structure has been improved, energy consumption in China has been mainly on coal, oil is complementary pattern of typical traditional energy consumption. The two primary energy consumption while growth speed is slow, but because of its base is bigger, the proportion can be accounted for about $80 \%$ of the total primary energy consumption in China - about $90 \%$. And other one-time energy: natural gas, nuclear power, hydro power and renewable energy while growth rate faster, but because of its small base, and its development is affected by a lot of technology, the proportion is only $10 \%-20 \%$.

Energy consumption in our country exist the following problems:

I.The huge energy consumption, energy demand potential growth at the same time;

II.Serious unreasonable energy consumption structure, coal consumption ratio is too large, about $70 \%$, but compared with developed countries, oil and natural gas consumption is low;

III.Nuclear energy and renewable energy development is rapid, but its amount is low.

\section{ANALYSIS OF CHARACTERISTICS OF AMERICAN ENERGY CONSUMPTION}

\section{A. America's total energy consumption analysis}

Table 3-The total energy consumption from 2003 to 2013, the United States

\begin{tabular}{lllllll}
\hline Year & 2003 & 2004 & 2005 & 2006 & 2007 & 2008 \\
\hline Gross & 2297.8 & 2344.7 & 2336.6 & 2326.4 & 2361.4 & 2299 \\
\hline Year & - & 2009 & 2010 & 2011 & 2012 & 2013 \\
\hline Gross & - & 2182 & 2285.7 & 2269.3 & 2208.8 & 2265.8 \\
\hline
\end{tabular}

Data sources: China natural gas industry network

( http://www.cngascn.com/html/news/show_news_w1_1 _29929.html) 
Table 4-2003-2003, the United States all kinds of oneoff energy consumption structure $(\%)$

\begin{tabular}{lllllll}
\hline Year & $\begin{array}{l}\text { Crude } \\
\text { Oil }\end{array}$ & $\begin{array}{l}\text { Natural } \\
\text { Gas }\end{array}$ & Coal & $\begin{array}{l}\text { Nuclear } \\
\text { Energy }\end{array}$ & $\begin{array}{l}\text { Hydro } \\
\text { Power }\end{array}$ & $\begin{array}{l}\text { Renewabl } \\
\text { e Energy }\end{array}$ \\
2003 & 39.8 & 24.7 & 25 & 7.9 & 2.7 & \\
2004 & 40.5 & 24.8 & 24.1 & 8 & 2.6 & \\
2005 & 40.4 & 24.4 & 24.6 & 8 & 2.6 & \\
2006 & 40.4 & 24.4 & 24.4 & 8.1 & 2.8 & \\
2007 & 39.9 & 25.2 & 24.3 & 8.1 & 2.4 & \\
2008 & 38.5 & 26.1 & 24.6 & 8.4 & 2.5 & \\
2009 & 37.8 & 27 & 22.8 & 8.7 & 3 & \\
2010 & 37.2 & 27.2 & 23 & 8.4 & 2.6 & 1.7 \\
2011 & 36.7 & 27.6 & 22.1 & 8.3 & 3.3 & 2 \\
2012 & 37.1 & 29.6 & 19.8 & 8.3 & 2.9 & 2.3 \\
2013 & 36.7 & 29.6 & 20.1 & 8.3 & 2.7 & 2.6 \\
\hline
\end{tabular}

Data sources: China natural gas industry network

( http://www.cngascn.com/html/news/show_news_w1_1 29929.html)

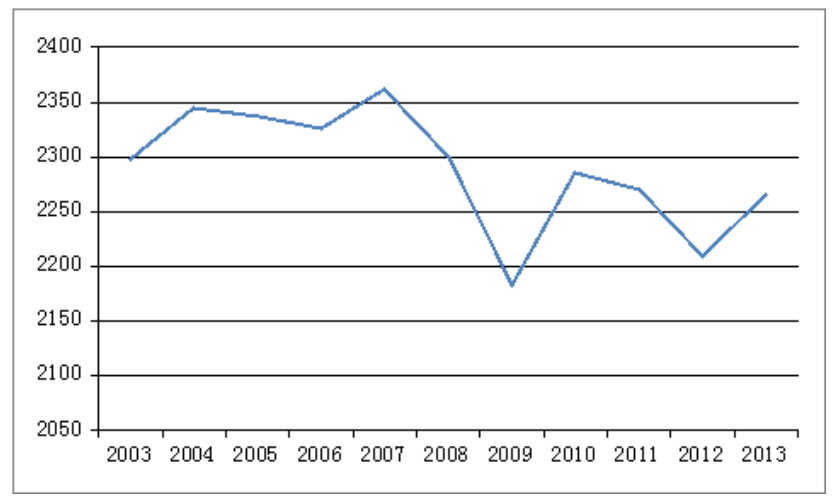

Figure 2-2003 to 2013, the total energy consumption in the United States

By figure 2 can see clearly the total energy consumption in the United States reached a peak in 2007, 2003 and 2007, total energy consumption increases by $2.7 \%$, the energy consumption in 2008 compared to 200 fell by $2.6 \%$, in 2009 fell to a low, fell by $7.6 \%$ compared with 2007 , after the average speed growth at the rate of only $0.9 \%$, to 2013 energy consumption level also did not return to 2003 levels of energy consumption, a fall of $1.4 \%$ compared with 2003.

B. Analysis of characteristics of the composition of America's energy consumption

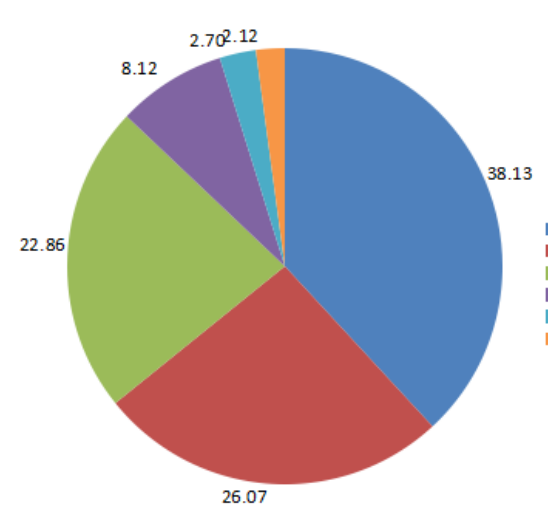

-Crude Oil Nat Gas Woal Hydro Power Renewable Energy

Figure 3-2003-2003, the United States a one-off energy consumption ratio $(\%)$
By figure 3 is obvious, the energy consumption is mainly composed of crude oil, natural gas, coal, nuclear energy, hydro power and renewable energy, including oil consumption has been the dominant, about $38.13 \%$ of the total energy consumption. Followed by natural gas and coal consumption, the consumption to around $50 \%$ of the total energy consumption. , hydropower and nuclear power and renewable energy consumption accounted for about $13 \%$. From that America's energy consumption structure based on crude oil consumption is given priority to, natural gas and coal is complementary the typical developed economy of the country's energy consumption patterns.

\section{The growth of the U.S. energy consumption characteristics analysis}

From 2003 to 2013, the United States the total energy consumption while peaked in 2007, but overall is a downward trend, including crude oil, raw coal consumption is decreased, the percentage decline $7.8 \%$ and $19.6 \%$, respectively. And natural gas, nuclear energy and renewable energy consumption is on the rise, the rise of $19.8 \%, 5.1 \%$ and $5.3 \%$ respectively, hydroelectric power, although there is a small fluctuations, but the change is not large, the average consumption of 2.7 million tons of oil equivalent, accounted for $2.7 \%$.

IV. ANALYSES THE ENERGY CONSUMPTION OF CHINA AND THE UNITED STATES SINCE 2003

A. The proportion of different varieties of energy consumption characteristics

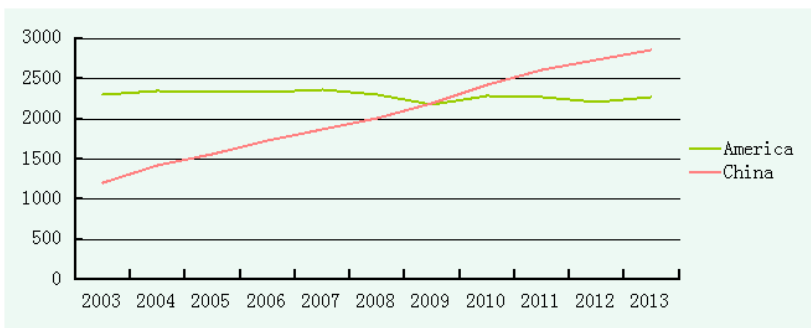

Figure 4-2003 and 2013, the total energy consumption trend analysis in China and the United States

From figure 4, you can see that the total energy consumption in China are lower than in the us before 2008, but due to the continued growth of energy consumption in our country has been and the energy consumption at a relatively low growth rate of growth or even a downward trend, the total energy consumption in our country than the United States in 2009, after still maintaining high growth rate, has become the United States in 2013 to the 1.26 times.

From figure 1 and figure 3 , you can see that our country's primary energy sources consumption proportion with the United States there is a huge difference, the energy consumption structure exists serious imbalance in our country, excessive dependence on the traditional fossil fuel resources, and new energy consumption is small, only accounts for $7.78 \%$ of energy consumption in our country. Our country coal consumption proportion is $69.41 \%$, the United States is $22.86 \%$. U.S. oil consumption reached $38.13 \%$ of the total energy consumption, and China is only $19.25 \%$, twice the U.S. oil consumption is about our country. 
To sum up, the differences of energy consumption in our country and developed countries, we should increase the crude oil, natural gas and new energy consumption, so that is our country in the next few decades can get rid of the traditional pattern of energy consumption, make the economic development of our country is not restricted by traditional energy stocks.

\section{B. The growth of energy consumption characteristics}

Although the total energy consumption in the United States fell, but its consumption of natural gas and new energy is still growing, the decline in consumption of crude oil, raw coal, it can be seen that the United States is in the energy structure adjustment, increase the exploitation and utilization of new energy, to reduce its dependence on oil. And with a large range of new energy consumption growth in China, but because of its small base, its consumption rate is still relatively small. Our country also should actively take measures to adjust the energy structure, the adjustment should not be a temporary, and should be continued for a long time, of course, this also is a long process.

\section{New energy consumption characteristics of the contrast}

The United States from 2003 to 2013 new renewable sources of energy consumption in energy consumption at an average annual 48.425 million tons of oil equivalent, but our country is only an average of 22.3 million tons of oil equivalent, is only $25 \%$ of that in the United States. China's nuclear power consumption is only an average of 15.9 million tons of oil equivalent, and the U.S. nuclear power average annual consumption of 188 million tons of oil equivalent, about 12 times for his country; Average annual consumption of 78.44 million tons of oil equivalent, natural gas in China and the United States for 603.76 million tons of oil equivalent, which is about 7.7 times of our country.

To sum up, our country new energy consumption is much lower than the United States consumption, not only in the proportion of total energy consumption is lower, the total amount is lower than the United States.

\section{Economic dependence on the energy characteristics of contrast}

Economic growth for energy resources dependence is very strong, high economic growth at the same time, the energy consumption is growing by leaps and bounds. 2008 U.S. energy consumption was decline is due to the impact of the subprime crisis, cause a setback for the U.S. economy, so the United States in 2009 fell to a new low energy consumption. Energy supply is largely determines the development of economy, with the development of world economy, the energy crisis also appear continuously, is likely to be a bottleneck of economic development, and the bottleneck is energy supply. Therefore, our country should not be development bottleneck constraints, have to adjust the energy consumption structure, actively develop new energy, reduce our dependence on traditional energy.

\section{CONCLUSIONS}

\section{A. Problems in China's energy consumption structure analysis}

I.Faster economic growth and energy shortage contradiction between:

Look from our country's economic development model, the economic development of our country mainly is based on the growth of fossil energy, drive economic growth lies in notting have is not energy-intensive industries at the core of the industry. Our country over the past 30 years to maintain high economic growth, which also led to the rapid rise in demand for energy. But, in the economic development in the future, if you want to keep this kind of growth, energy security is the most important, this is the objective demand of economic growth in our country faces. But China's extensive resource utilization pattern and energy utilization which leads to the energy of structural shortage of our country appears a series of crisis.

Although China is a vast land, rich in energy reserves, but China's per capita energy resources ownership is low, coal and water resources per capita is only equivalent to $50 \%$ of the world's average level, oil and natural gas resources per capita ownership is only about $1 / 15$ of the world average. Energy resource enrichness unbalanced development is difficult, has proved a serious shortage of high-quality energy such as oil, natural gas reserves. Coupled with energy utilization technology lag behind, the use of low, under the condition of high economic growth, China's energy consumption faster than other countries, the threat of energy depletion could come earlier and more serious.

II.Traditional mainly on coal consumption of the contradiction between the energy consumption structure and the environment worsening:

For a long time is given priority to with coal energy structure and single energy consumption pattern has brought serious environmental pollution. Along with the rapid development of economy and sustained growth of energy demand and greenhouse gas emissions produced by the burning of fossil fuels has caused more and more heavy pressure on the environment. Facing the current fossil energy consumption brings serious environmental crisis, adjust the energy structure is imminent.

At home and abroad is generally believed that a large number of greenhouse gas emissions lead to global climate change, increased heat waves, floods, drought, storm frequency and intensity. In the greenhouse gases blamed for climate change, carbon dioxide is the main ingredient. With the speeding up of industrialization in our country, the air quality worse and worse; Haze weather increases, the frequency of the unusual weather now, to China's energy consumption structure is a wake-up call at a time. And sustainable development in China at present, in the five major challenges facing the total energy demand large and rapid growth, an increasingly tense supply capacity; Greenhouse gas emissions are huge and rapidly increasing; In rural areas and small towns in urgent need of a large number of clean and convenient energy services; Conventional serious environmental pollution; Shortage of liquid fuels, is highly dependent on imports, energy security; Five challenges in both with the ring. 


\section{B. Compared to the United States we what deficiencies and solutions}

I.The deficiencies analysis:

As the world's largest energy consumer, fossil fuels has always been the United States consumes the most energy resources. In recent years, the external energy dependence is gradually reduced, energy production and consumption structure changed dramatically. Green energy in the United States, the United States energy consumption: strengthening of nuclear power, wind power and solar energy development and utilization of clean energy and improve energy utilization efficiency, realize the energy conservation and emissions reduction, reduce our dependence on oil. In the United States under the government's policy support, nuclear energy and renewable energy in the United States to get fast development.

As the second largest energy consumer, China coal is the main energy consumption in our country, but at the same time to the pressure of environmental governance in China is huge. A growing energy structure in China can't develop for a long time, China's energy structure is facing a deep crisis, the traditional mode of economic growth has come to an end. China's energy consumption and the consumption level still has a large gap, in many ways, energy waste are still serious. In general we have not get out of to high growth, high consumption high pollution, extensive expansion and predominantly epitaxial growth.

II.How to improve the present situation of energy consumption

a.Increase the development and utilization of renewable energy

Have the advantage of the with abundant resources of renewable energy in China, is an important strategic alternatives, to increase energy supply, improve the energy structure, energy security, protect the environment plays an important role. Positive development and utilization of nuclear energy, solar energy, wind energy, electrical energy, biomass energy, geothermal energy and ocean energy and other renewable energy sources, is to achieve the inevitable choice of China's economic and social sustainable development energy strategy.What's more,Renewable energy has a good market in China.

b.Improve energy utilization

Energy consumption in our country, there is also a great problems in energy efficiency is low, it is lead to severe energy waste in our country, and the low utilization rate of waste emissions, the effects on the environment is very bad. Therefore, energy efficiency, adjust the industrial structure. Promote the development of the third industry, reduce the dependence of national economy of high energy intensity of industrial.

c.Research on coal clean utilization technology

Coal reserves in our country the world's top three, coal consumption, the world, but because of the environment caused by the coal is very serious. Clean utilization of coal, so the technology, such as supercritical power generation technology, the overall coal gasification technology, gas and steam combined cycle, $\mathrm{CO} 2$ capture, oxygen-enriched combustion technology and correctly guide the rational consumption, clean coal consumption. Simulated ecosystem function, the establishment of "reduction" producers, consumers, mining production chain.

d.The development of shale gas

Shale gas mined from shale is a very important unconventional gas resources, is compared to conventional gas, shale gas development has a long service life and long production cycle, most of the gas shale distribution range, thickness, and the common gas, which makes the shale gas well to long-term gas at a steady rate. The world energy research institute (WRI), a new study suggests that up to 30 trillion cubic meters, shale gas reserves in China first in the world, is almost twice as much as in the United States.

So we can draw lessons from the successful experience of American shale gas development, the development of unconventional oil and gas resources, reduce oil dependence degree abroad.

\section{REFERENCES}

[1] Aiyuan. Tao the China economic growth dependent on energy analysis of CSSCI and decision of statistics in 2007, the second phase

[2] The general situation of the whole world energy analysis our country current energy problems we are facing and how China should face the energy crisis"K. Elissa, "Title of paper if known," unpublished.

[3] Su-qin wang. "the environmental problems caused by the coal industry in Shanxi Province and countermeasures" SCI "intelligence development of science and technology and economy" in 2006, 16 (10)

[4] FeiYunXiang Guo Pibin the relationship of energy consumption structure and economic growth in China research on CSSCI "science and technology management research" 23, 2013

[5] The world's energy giant, competing in the market of Chinese clean energy pouring the qinghai province science and technology, 2014

[6] The trend of China's energy structure adjustment, the western resources, 2014, 2

[7] Liu Lei ,Jin jing, Qing-qing Zhao, Zhang Yingwen Liu, China and the world primary energy consumption structure status quo analysis of the energy research and information technology (30) 